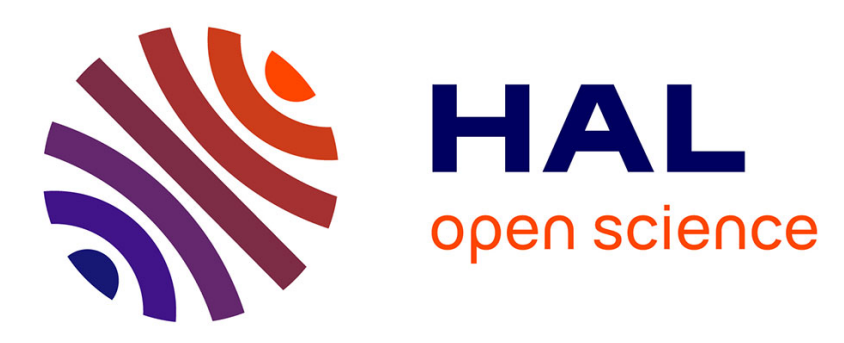

\title{
A decision support system for integrated tourism development: rethinking tourism policies and management strategies
}

\author{
J.P. Bousset, D. Skuras, J. Tesitel, Marsat J B, A. Petrou, E. Fiallo-Pantziou, \\ D. Kuová, M. Barto
}

\section{To cite this version:}

J.P. Bousset, D. Skuras, J. Tesitel, Marsat J B, A. Petrou, et al.. A decision support system for integrated tourism development: rethinking tourism policies and management strategies. Tourism Geographies, 2007, 9 (4), p. 387 - p. $404.10 .1080 / 14616680701647576$. hal-00452219

\author{
HAL Id: hal-00452219 \\ https://hal.science/hal-00452219
}

Submitted on 1 Feb 2010

HAL is a multi-disciplinary open access archive for the deposit and dissemination of scientific research documents, whether they are published or not. The documents may come from teaching and research institutions in France or abroad, or from public or private research centers.
L'archive ouverte pluridisciplinaire HAL, est destinée au dépôt et à la diffusion de documents scientifiques de niveau recherche, publiés ou non, émanant des établissements d'enseignement et de recherche français ou étrangers, des laboratoires publics ou privés. 


\section{A Decision Support System for Integrated Tourism Development: Rethinking Tourism Policies and Management Strategies}

Jean-Paul Bousset* ${ }^{1}$, Dimitris Skuras ${ }^{2}$, Jan Těšitel ${ }^{3}$, Jean-Bernard Marsat ${ }^{1}$, Anastasia Petrou $^{2}$; Elba Fiallo-Pantziou ${ }^{2}$, Drahomíra Kušová ${ }^{3}$ and Michael Bartoš ${ }^{3}$

${ }^{1}$ Dynamics and Functions of Rural Areas, Cemagref, 24 avenue des Landais - BP 50085 63172 Aubière Cedex, France. Tel.: 334734406 46, Fax 334734406 98, Email: jean-paul.bousset@cemagref.fr

${ }^{2}$ Department of Economics, University of Patras, Greece. Tel: + 302610 996130, Fax: + 30 26110 996265, E-mail: skuras@econ.upatras.gr

3 ISBE AS CR, Na Sádkách 7, 37005 České Budějovice, Czech Republic. Tel.: +420 387775 670, Fax: +420 385310 249, Email: jante@usbe.cas.cz

Jean-Paul Bousset is a researcher at the Dynamics and Functions of Rural Areas Research Unit of Cemegref. He was a member of the French team in the SPRITE project.

Dimitris Skuras is Associate Professor, Department of Economics, University of Patras. Tel: +302610 996130, Fax: + 3026110996265. He was a member of the Greek team in the SPRITE project.

Jan Těšitel is a researcher at the Landsape Ecology Department of the Institute of Systems Biology and Ecology, Academy of Sciences, Czech Republic. He was a member of the Czech team in the SPRITE project 
Jean-Bernard Marsat is a researcher at the Dynamics and Functions of Rural Areas Research Unit of Cemegref. He was a member of the French team in the SPRITE project. Tel.: 33473440655 Fax: 33473440698 Email: jean-bernard.marsat@cemagref.fr

Anastasia Petrou is a research assistant, Department of Economics, University of Patras. She was a member of the Greek team in the SPRITE project. Tel: + 302610 996270, Fax: + 3026110996265 , E-mail: apetrou@upatras.gr

Elba Fiallo-Pantziou is a research assistant, Department of Economics, University of Patras. She was a member of the Greek team in the SPRITE project. Tel: + 302610 996270, Fax: + 3026110996265 , E-mail:efialloc@upatras.gr

Drahomíra Kušová is a researcher at the Landsape Ecology Department of the Institute of Systems Biology and Ecology, Academy of Sciences, Czech Republic. She was a member of the Czech team in the SPRITE project. Tel: +420 387775 670, Fax: +420 385310249. Email: draku@usbe.cas.cz

Michael Bartoš is a researcher at the Landsape Ecology Department of the Institute of Systems Biology and Ecology, Academy of Sciences, Czech Republic. He was a member of the Czech team in the SPRITE project. Tel: +420 387775 670, Fax: +420 385310249. Email:michlba@usbe.cas.cz

* Contact person 


\section{A Decision Support System for Integrated Tourism Development: Rethinking Tourism Policies and Management Strategies}

ABSTRACT Identifying the most appropriate institutional structures and strategies to integrate the views and coordinate the actions of diverse tourism stakeholders is a key stage in the development of integrated tourism in rural and lagging areas. In this work a Decision Support System (DSS) is developed which combines tools to assist in the analysis of the views, concerns and planned strategies of a wide range of tourism stakeholders in the face of given trends in tourists' expectations. The role and suitability of such an approach is examined in the real situation of three case-study areas in Auvergne (France), Šumava Mountains (Czech Republic) and Evrytania (Greece). Two major sets of results are discussed. Firstly, there are the impacts of given hypothetical tourism policies developed by simulating the views and strategies of the different tourism stakeholders. Secondly, the paper considers the relative benefits and disadvantages for integrated tourism if collaborative negotiations take place among the different tourism stakeholders. The paper concludes by examining the usefulness of such an approach for tourism planners.

KEY WORDS: Integrated tourism, policy formulation, participatory approaches, simulation models, Decision Support Systems 


\section{Introduction}

Links between tourism and local and regional resources, activities, products and communities are key success factors for integrated tourism development. A key stage of the policy process involves the identification of institutional structures and strategies that are most appropriate to integrate the views and to coordinate the actions of resource controllers, tourism businesses, gatekeepers, host communities, and institutions in the light of given trends in the tourists' expectations. The successful completion of this stage can be assisted by a Decision Support System (DSS) developed to analyse the perspectives and planned strategies of the tourism stakeholders and to assess, through simulation tools, the impacts of hypothetical tourism policies.

This paper discusses the operation and suitability of such a DSS in designing and implementing policies for integrated tourism, through a comparative study of its application in three predominantly rural and lagging areas of the European Union. In subsequent sections, the conceptual framework underlying the design of the DSS is presented. Support tools for the creation of policies integrating the views and strategies of tourism stakeholders are formulated. The views and strategies of the different tourism stakeholders are simulated and the impacts of given hypothetical tourism policies are assessed. The relative advantages and disadvantages of collaborative negotiations among the tourism stakeholders for the development of integrated tourism are examined. The paper concludes by assessing the usefulness of the DSS for tourism planners, and suggests areas for future research. 


\section{Conceptual Framework}

This section provides a brief description of working concepts used in creating tools for the identification of institutional structures and strategies which integrate the views of the different tourism stakeholders.

Most of the concepts are linked to the 'participatory integrated policy (PIP) formulation' and 'multi-agent simulation (MAS)' methodologies. PIP formulation methods are designed to involve multiple stakeholders in consultation and negotiation processes that harmonise their conflicting objectives, strategies and capacities (Campbell \& Townsley, 1997). The PIP methodology draws its fundamental information from interviews with individual stakeholders and scenario workshops. Scenario workshops are meetings that bring together policy-makers and stakeholders for the analysis of pre-constructed scenarios, which describe the possible impacts of hypothetical events and policies (Street 1997). The aims of using PIP methodologies are functional and empowering. Functional aims are those concerned with the ex ante impact assessment of hypothetical policies (scenario construction). Possible future impacts of the tested tourism policies may come from the results of MAS models, which offer a convenient framework for exploring the ways for different stakeholders with multiple views to negotiate their interests and create social constructions in order to take part to the policy process (Bousquet, 1997). Such an approach is now widely accepted for studying processes involving multi-stakeholder management systems and can be used for the construction of computer systems intended to provide support to decision makers engaged in solving semi- or ill-structured problems involving multiple attributes and various data-treatment models (Barreteau et al., 2003; Happe et al., 2006). 
Empowering aims are those targeting the collecting of information related, firstly, to the collective learning capabilities of scenario workshops (Godet, 2001) and, secondly, to the influence that actors affected by a future tourism policy can exercise on the specification of the objectives and implementation of this policy (Stokman and Zeggelink, 1996 ; Gurung et al., 2006). Scenario workshops assume that the different parties search for a common definition of the problem and then generate a set of possible solutions broad enough to allow them to find the one that incorporates at least some of the interests of each stakeholder. As stakeholders share their individual appreciations about the problem, a more comprehensive understanding of the problem will emerge. Finally, in the face of assessments that differ from their own, individual stakeholders will have the opportunity to expand and revise their interpretation and escape the constraints imposed by their own feasibility preoccupations. In doing so, scenario workshops can provide policy-makers with alternative perspectives and recommendations, which constitute informative material for the formulation of policies.

\section{Case-Study Areas, Scenario and Data}

\section{Case-study areas}

Three case-study areas in the European Union were selected to test the DSS, namely the Auvergne region (France), the Šumava Mountains (Czech Republic) and Evrytania (Greece). All these areas are mountainous, remote from their main national centres of economic activity and suffer from several development constraints. The three study areas are predominantly mountainous and with an image of places of outstanding natural beauty where tourists can enjoy nature and relax. In all three areas, the development of rural tourism is considered a viable rural-development strategy that can strengthen and diversify the economic activity 
base. As a result, the study areas in France and Greece have been targeted for a long time by the European Union's rural development policy instruments and initiatives, while rural tourism development in the Šumava Mountains has been subject to Czech national policies. However, the three areas differ significantly, firstly, in terms of the intensity of tourism development and consequently in their dependence on rural tourism as an activity generating income and employment and, secondly, in the way cultural resources, mainly cultural and culinary heritage, are valorised and embedded in the tourism service. Cultural heritage resources are used more intensely in the Auvergne area than in the Šumava Mountains or Evrytania. Tourism, in terms of infrastructure and human-made resources, is more developed in Evrytania than in the other two study areas. In addition, because of differences in local and regional government structures, the three areas differ in terms of the institutional environment available for, and the perspectives towards tourism development. Despite the presence of a national park, institutional structures for tourism are rather less developed in Šumava Moutains than in the other two areas.

\section{Hypothetical scenario and coordination patterns}

The future is always uncertain. However, it is possible to formulate scenarios which can offer insights into possible future developments. The SPRITE DSS provides policy-makers with tools for the construction of such scenarios. In our project, scenarios describe, firstly, the driving forces for the future that affect tourism development in a given area and, secondly, the consequent impacts of these forces on the development of integrated tourism.

The driving forces of tourism development in a given area may be either external or internal. External forces are hypothetical changes in the general conditions surrounding tourism, 
which in this paper are called 'events'. External forces are not influenced or controlled by tourism stakeholders in a specific area. The continuous increase in petrol prices affecting travel costs or the increase in terrorist actions affecting transportation modes are examples of external forces influencing tourism development. In this work we analysed the following event. "The quality of the natural and cultural environment is becoming increasingly important to people generally, and the expectations of visitors to the study regions about the quality of the natural and cultural environment are increasing strongly hence they are less inclined to tolerate its neglect".

Internal forces include: 1) the resources and products available to tourism development in a specific area; 2) the resources, views, and strategies of the individual actors involved in the tourism development of the area; 3) the hypothetical coordination patterns governing the interactions among tourism stakeholders and between stakeholders and local resources. Hypothetical coordination patterns to be evaluated include:

- no change in the current tourism policies;

- a policy supporting more the provision of local resources for tourism;

- a policy supporting more control of local resources;

- a policy supporting more the supply of local tourism products;

- a policy supporting more the promotion of local products and places;

- a policy for more cooperation between resource controllers, tourism businesses and gatekeepers to develop tourism;

- a collaborative negotiations process among the different tourism stakeholders.

The evaluation of the coordination pattern with no change in current tourism policies provides what is called here the 'baseline scenario'. The evaluation of coordination patterns, 
including a hypothetical tourism policy, provides the 'alternative policy scenario'. The baseline scenario describes the possible future impacts of the event under consideration on the use of local resources, communities, and integrated tourism, if there is no change in the current policies, i.e. the normal evolution of tourism without any additional policies. The alternative policy scenarios describe the possible future impacts of the event under consideration on the use of local resources, communities and integrated tourism, if alternative policies are employed. Following closely the SPRITE concepts of integrated tourism, the impacts of the examined coordination patterns are expressed in terms of scale, endogeneity, complementarity, empowerment and policy networking.

\section{Data}

The data for this work come from two distinct sources. First, a questionnaire survey addressed a sample of individual tourism stakeholders. Second, scenario workshops gathered together a small group of tourism development specialist in each study area.

The questionnaire survey collected information concerning the resources and products available to develop tourism in the area, as well as the resources, views and strategies of individual tourism stakeholders. The sample of tourism stakeholders comprised about 50 tourism-related businesses, 50 tourism-related gatekeepers, 10 tourism institutions, 20 resource controllers, 50 members of the host communities, and 100 tourists in each casestudy area.

Questionnaires were structured in four sections recording available resources, views, expectations and attitudes. The first section included questions identifying the resources of 
individual actors (denoted by $\mathrm{r}^{\mathrm{i}}$ ), such as the number of employees, turnover and current networking. The second section recorded the actors' views and perceptions towards the importance of local resources for tourism (denoted by $\mathrm{v}^{\mathrm{i}}$ ), and towards the importance of the scenario event in relation to their own operation (denoted by $s^{i}$ ). The third section of the questionnaire recorded the actors' expectations regarding the future changes in conditions surrounding tourism when present conditions are taken into account (denoted by $\mathrm{x}^{\mathrm{i}}$.) and the ways that should be used to support these expected changes were recorded (denoted by $\mathrm{e}^{\mathrm{i}}$ ). The fourth section of the questionnaire recorded the actors' attitudes or behaviour towards a series of issues related to integrated tourism (denoted by vi $\mathrm{i}^{\mathrm{i}}$ )

Scenario workshops that operated in each area collected comments and critiques from policymakers, representatives of tourism stakeholders and tourism experts on the proposed scenarios, developed participants' own visions and proposals, and formulated policy recommendations.

\section{Impacts of given Hypothetical Policies on Integrated Tourism}

This section presents the methodology used to simulate the various strategies and interactions of different sets of tourism stakeholders in the face of given new, hypothetical policies (see above: Hypothetical scenarios and coordination patterns). The consequences of these simulations for the development of integrated tourism in the study areas of Auvergne (France), Šumava Mountains (Czech Republic) and Evrytania (Greece) are examined.

\section{Simulation methodology}


Impacts of hypothetical policies are evaluated by simulating the decision-making logic of resource controllers, tourism businesses and gatekeepers in the context of such policies, then by simulating the decision-making logic of host-community members and tourists in the face of the actions of the other tourism stakeholders.

The simulated decision-making logics specify the role of the resources, views, expectations and attitudes of tourism stakeholders when deciding what their reactions will be concerning the use of local resources and tourism products, taking into account the given events and policies and the other stakeholders' reactions and decisions. The latter vary according to the functions of the actors involved in tourism development (Jenkins and Oliver 2001).

Assembling the decision-making logics of the different sets of tourism stakeholders one creates a 'multi-stakeholder, decision-making model'. Each simulation of such a decisionmaking model involves five stages: initialisation, provision, integration, promotion and consumption. The last four stages are sequentially and iteratively estimated ten times in order to simulate a long policy period. Each stage of the simulation process is briefly described and explained below. The interested reader may find a more detailed presentation in Bousset et al. (2003).

Initialisation. The initialisation phase creates a hypothetical space (grid) that represents the study area and reflects the spatial variation in resources and products existing among the interviewed stakeholders. The initialisation phase includes two steps. The first step consists of examining the individual resources $\left(\mathrm{r}^{\mathrm{i}}\right)$, political expectations $\left(\mathrm{x}^{\mathrm{i}}, \mathrm{e}^{\mathrm{i}}\right)$, perceptions of the event $\left(\mathrm{s}^{\mathrm{i}}\right)$ and of the potential of local resources for tourism development $\left(\mathrm{v}^{\mathrm{i}}\right)$ of stakeholders, and the actors' attitudes or behaviour towards issues related to integrated tourism (vi ${ }^{\mathrm{i}}$ ). The 
second step consists of allocating each stakeholder a place within the hypothetical space according to his/her endowment of resources and/or products.

The provision, integration and promotion phases of the simulation process re-locate within the hypothetical space those resource controllers, businesses and gatekeepers who support the hypothetical event and believe that the tested policy is the best way to achieve it.

Provision. The provision phase re-locates each resource controller that conforms to the aforementioned criteria to places within the hypothetical space endowed with natural or cultural resources not yet available for tourism development.

Integration. The integration phase re-locates tourism businesses that conform to the aforementioned criteria and usually integrate natural or cultural resources into their tourism products. They move to places within the hypothetical space endowed with resources accessible but not yet integrated into tourism products.

Promotion. The promotion phase re-locates gatekeepers that conform to the aforementioned criteria to places in the hypothetical space endowed with resources and products that are not yet promoted.

The screening-out process employed in the provision, integration and promotion stages to relocate the stakeholders within the hypothetical space is based on the stakeholders' responses to specific questions in the questionnaire. The process includes three stages: censing, assessment, moving. The censing stage selects the stakeholders who agree with tourism development and believe that the presented policy option is the best way to achieve this goal. The assessment stage counts the number of tourists who visited the places where resources had been made more accessible, integrated and promoted by those stakeholders since the 
beginning of the simulation. If the number is decreasing, then some supporters of the tested policy stop searching for new places to operate. If the number is increasing, some stakeholders who agree with tourism development but believe that the tested policy is not the best way to develop tourism, become supporters of that policy and search for places to operate. The moving stage consists of re-locating the supporters of the tested policy among the parts of the hypothetical space that have not yet been made more accessible, integrated and promoted. If a supporter is found alone in such a place, then this actor continues to operate. Otherwise, only the actor with the most resources operates in that place and the other actors move to other places. By this mechanism one can simulate the growth and spread of integrated tourism in a competitive environment.

Consumption. The consumption phase assigns new tourists to places in the hypothetical space. It is assumed that new tourists come to the area for the quality of its natural and cultural resources and search the area to find a place that matches their expectations before starting to consume their tourism experience. The new tourists are located to places in the hypothetical space where the natural or cultural resources have been made accessible by resource controllers, integrated in tourism products by businesses, and promoted by gatekeepers. The tourists stay in these places, provided that the density of tourists in these places is not greater than a given threshold (congestion) and the local host-community members are in favour of tourism development. Otherwise, they move to another place. If a new tourist cannot be assigned by the algorithm to any place that satisfies his/her expectations, it is assumed that he/she leaves the area and does not return. Hence the effects of congestion and host-community resistance are built into the model.

At the end of the simulation, the model examines the potential of the coordination pattern under consideration to make the natural and cultural resources more accessible for tourism 
(the impact on endogeneity), for integrating and promoting the tourism products (impacts on complementarity), for facilitating a greater number of visitors (impact on scale), for challenging reluctant actors to support the policy, and for identifying conflicts among stakeholders and tourists (impacts on local empowerment).

\section{Case-study results}

Impacts of the tested policies in Auvergne (France). In Auvergne, the coordination patterns concerning more support for the supply of local tourism products (products-supply policy) and institutional support for more cooperation between resource controllers, tourism businesses and gatekeepers to develop tourism (actors-cooperation policy) both have greater impacts on the development of integrated tourism than any of the other tested coordination patterns. This result is due to the fact that the networks supporting these two policies are better resourced, i.e. their members have a higher level of resources and a higher willingness to mobilise their resources towards the achievement of their goals, than is the case with the policy networks supporting other coordination-pattern policies.

However, the differences between the impacts under these two coordination patterns and the coordination pattern assuming no change in the current tourism policies are not large. This is because almost all resource controllers tend to disagree with tourism development as a policy. Consequently, irrespective of the tested coordination pattern, tourism businesses and gatekeepers wishing to develop tourism do not find enough accessible natural and cultural resources to do so. This is an important finding indicating that, if the hypothetical event is realised, businesses and gatekeepers on the one hand and tourists on the other will overconcentrate in that limited number of places where development is allowed by the resource 
controllers. This over-concentration will put at risk the area's image as an uncongested place where tourists can relax.

In addition, irrespective of the coordination pattern used, the impacts on integrated tourism development are not very important. This is partly due to the consequences of the disagreements among the resource controllers, already mentioned. It is also partly due to the fact that whereas the majority of businesses and some gatekeepers would support a coordination pattern providing more tourism products, the majority of gatekeepers and some businesses would support a coordination pattern that provided for the better promotion, instead of the increased supply, of tourism products. This asymmetry results in the supply and promotion of only a few new tourism products. This again is an important finding, indicating that attitudinal asymmetries between businesses and gatekeepers may constrain the further diversification of the area's tourism product, leading to a higher degree of specialisation in a narrow range of tourism products.

Participants in the scenario workshops recognised such future behaviours as realistic presumptions to be taken into account when thinking of the future development of tourism in the Auvergne area. The participants stressed the lack of support from forest owners, industries and banks for tourism development. They underlined the lack of support from local institutions in promoting the resources of the area, they emphasised the lack of professional skills in tourism businesses and gatekeepers, and highlighted the absence of an institutional forum for the representation of the various tourism-related actors. The participants suggested a wide range of measures for the development of integrated tourism, including the creation of more specific linkages between tourism products and local natural resources (e.g. houses in forests, gastronomy using mushrooms, etc.), and the creation and 
promotion of a regional imagery that emphasises more fully the quality of the area's natural resources.

Impacts of the simulated policies in Šumava Mountains (Czech Republic). As in the Auvergne area, the actors-cooperation policy in the Šumava Mountains appears to be the best policy to develop integrated tourism. However, this result is due to the fact that this policy has the potential to generate fewer conflicts than other policies and not because it is supported by a better-resourced policy network, as was the case in the Auvergne.

In the Šmava Mountains, all the tested coordination patterns have greater impacts on the use of natural and cultural resources for tourism development than in the Auvergne. This is because, compared with the Auvergne, higher proportions of the resource controllers, businesses and gatekeepers have a strong interest in tourism, a positive opinion of the role of these resources for tourism development, and a positive opinion on the impacts of the tested policies on integrated tourism. However, simulations indicate that such tourism development might generate a great deal of conflict among tourism stakeholders and new tourists.

The outcome of the simulated actors-cooperation model indicated that, in comparison with the coordination pattern implying no change in current policies, potential conflicts among individual actors decreased. This outcome was well received by scenario workshop participants. However, participants stressed that the real situation differs within the study area. Potential conflict, described by the alternative regulation scenarios, occurs mainly close to border crossings with Austria where a number of stallholders have appeared. These spots in particular and the zone in the vicinity of the state's border in general, have become popular with day tourists from Austria and Germany. Participants in the scenario workshops also 
stressed that tourism is recognised as the principal activity on which local development efforts should be based. Participants agreed that a market-economy perspective, mainly in terms of opportunities for development, is still regarded positively. Such opinions are closely related to the area's recent history, and especially to its ability to articulate its own ideas of tourism development from a bottom-up perspective. Participants also insisted that the quality of services provided should be given high priority. It was also suggested that quality services should be certified. Such quality certifications should be issued by an appropriate regional tourism chamber, which, unfortunately has not yet been established.

Impacts of the simulated policies in Evrytania (Greece). In Evrytania too, the actorscooperation policy appears to be the best policy for the development of integrated tourism. There are two reasons for this. First, the members of the network supporting this policy have a greater willingness to mobilise their resources than do the members of the networks supporting other coordination-patterns policies. Second, this coordination pattern generates more satisfaction among tourists than other policies. The actors-coordination pattern emerges in Evrytania as a request driven by demand-related actors, as distinct from the situation in the Auvergne where the same coordination pattern emerges as a request driven by supply-related actors.

The participants in the scenario workshops recognised such future behaviours as realistic presumptions that should be taken into account when thinking of the future development of tourism in the area. They stressed that the provision of new products and/or services, i.e. a development strategy based on product diversification, should not be regarded as a viable policy. Despite the economic benefits to those involved in tourism activities, further 
development of tourism may have negative distributional welfare impacts on those not directly involved in tourism activities, and this was expected to increase conflicts.

The participants emphasised that there are two major constraints acting against a future integrated tourism strategy. The first relates to the allocation of financial (and, in general, economic) resources among the actors as well as the allocation and distribution of benefits within the local communities. The second refers to the management of resources and the associated expertise needed to manage them in a sustainable way. Finally, participants pointed out that coordination patterns implying new regulations are not always viable, because the Greek economic environment is already over-regulated.

Study-area results - summary

To summarise the findings for the study areas, the simulations show that results are highly sensitive to the resources and preferences of the supporters of tourism development, as well as to the distribution of local resources. The impact of the tested policies on the accessibility of natural and cultural resources is increased when the level of local economic resources increases and when the actors' preferences are stronger for such resources to be used as a tool for tourism development. The impact of the tested policies on the promotion of tourism products linked to natural and cultural resources is lower when the level of the actors' preferences is stronger for social resources to be used as a tool for tourism development. The impact of the tested policies on tourist arrivals is high when the level of the actors' preferences is high for natural resources to be used as a tool of tourism development. The impact on tourist arrivals is low when the current tourist density and congestion are already 
high. Detailed data and tabulated results from the simulation exercises are available from the contact author upon request.

\section{Benefits and Disadvantages for integrated tourism of Collaborative Negotiations}

One of the critical determinants of the degree of integrated tourism is the extent to which the actors have a common set of goals and collaborate to achieve them. Hence, this section of the paper presents the ways used to simulate a collaborative-negotiation process among the different groups of tourism stakeholders. It then discusses the relative benefits and disadvantages of such a process for the development of integrated tourism in the study areas of Auvergne, Šumava Mountains and Evrytania.

\section{Simulation methodology}

The decision-making model used in the previous section to assess the impact tourism policies assumes that most of the tourism stakeholders have fixed views, attitudes and expectations towards policy initiatives. The collaborative-negotiations model assumes that all the stakeholders can change their views and policy preferences in order to secure a policy outcome that is as close as possible to their expectations on tourism development $\left(\mathrm{x}^{\mathrm{i}}\right)$ and resources availability, integration, promotion and actors' coordination $\left(\mathrm{e}^{\mathrm{i}}\right)$.

The simulation develops in four stages: initialisation, access evaluation and request, request evaluation and positions alignment. The last three stages are sequentially and iteratively estimated ten times to get the 'learning effects' of successive hypothetical scenario workshops. The function and operation of each stage of the simulation process are briefly 
explained below. The interested reader will find a more detailed presentation in Bousset et al. (2003).

Initialisation. The initialisation stage consists of capturing the stakeholders' own resources $\left(\mathrm{r}^{\mathrm{i}}\right)$, perceptions concerning the event $\left(\mathrm{s}^{\mathrm{i}}\right)$ and the importance of local resources for tourism $\left(\mathrm{v}^{\mathrm{i}}\right)$, attitudes or behaviour towards issues related to integrated tourism (vi ${ }^{\mathrm{i}}$, expectations from the goals of future tourism policy $\left(\mathrm{x}^{\mathrm{i}}\right)$ and the actions needed to achieve these goals $\left(\mathrm{e}^{\mathrm{i}}\right)$.

Access evaluation. During access evaluation, each stakeholder i identifies the other stakeholder $\mathrm{j}$ that he/she wants to approach with a view to persuading him/her to adopt his/her own policy expectations. We assume that one stakeholder i decision to contact another stakeholder $\mathrm{j}$ depends, firstly, on the perceived utility for $\mathrm{i}$ in challenging $\mathrm{j}$ to adopt his/her position and, secondly, on the expected probability that the stakeholder $\mathrm{j}$ will agree to this request, which depends on the utility for $\mathrm{j}$ to adopt the i's political positions. Utility for a given stakeholder $\mathrm{i}$ to challenge stakeholder $\mathrm{j}$ to adopt his/her own political position is assumed to increase according to the $\mathrm{j}$ 's resources $\left(\mathrm{r}^{\mathrm{j}}\right)$, importance of tourism $\left(\mathrm{s}^{\mathrm{j}}\right)$ and the differences between the i's and j's views on the goals of future tourism policy $\left(\left|x^{i}-x^{j}\right|\right)$, the actions needed to achieve these goals $\left(\left|\mathrm{e}^{\mathrm{i}}-\mathrm{e}^{\mathrm{j}}\right|\right)$, the importance of local resources for tourism $\left(\left|\mathrm{v}^{\mathrm{i}}-\mathrm{v}^{\mathrm{j}}\right|\right)$ and the attitudes or behaviour towards issues related to integrated tourism $\left(\left|\mathrm{vi}^{\mathrm{i}}-\mathrm{vi}^{\mathrm{j}}\right|\right)$. The complex algorithms for the exact estimation of the request's perceived utility and of the expected probability for agreement are presented in Bousset et al. (2003).

Requests evaluation. Request evaluation is the stage in which each stakeholder $\mathrm{j}$ decides either to accept or reject the requests to alter its policy coming from stakeholders $i_{1}$ to $i_{n}$. If stakeholder $\mathrm{j}$ accepts a request for cooperation from stakeholder $\mathrm{i}$, then the request becomes an access relation between $\mathrm{i}$ and $\mathrm{j}$. Stakeholder $\mathrm{j}$ will accept the policy-change request from 
stakeholder $i$ if $j$ believes that $i$ can't be persuaded to adopt $j$ 's position, if stakeholder $i$ is the costless challenger among all the possible challengers, and if stakeholder $\mathrm{i}$ is a member of a more powerful coalition than stakeholder $\mathrm{j}$ belongs to.

Positions alignment. During this phase, each stakeholder $\mathrm{j}$ who accepts a stakeholder i's request adopts the latter's political positions and informs the other stakeholders of that change. Next, all tourism stakeholders adapt their cognitive image of the policy domain and recognise the new positions of the challenged stakeholders. Consequently, they adapt their estimates of the expected outcomes of their political positions, their estimates of the power of the other stakeholders' coalitions (policy networks), and their estimates of the probabilities that future requests will be accepted. So, because access relations are re-evaluated at each iteration of the simulations, a given access relation can disappear if no new request is made or if the new request is no longer accepted.

At the end of the simulations, the model indicates the impact of the negotiation process on the following:

- the membership, structure and capacity of policy networks (impacts on networking);

- the inter- and intra-organisational linkages that might lead cooperative behaviour among tourism stakeholder to develop integrated tourism in their areas (impact on leadership);

- the potential for conflicts among the different groups of tourism stakeholders (impact on empowerment);

- and the sensitivity of the above results to selective exposure to information and to the willingness of the most powerful stakeholders to respond and negotiate with other actors.

Case-study results 
Impacts of the negotiation process in Auvergne (France). In Auvergne, simulations indicate that collaborative negotiations might induce only a few changes in the expectations of tourism stakeholders regarding the overall objective of future tourism policies. However, simulations did indicate a number of potential shifts on coordination patterns (preferred policy) to be used to develop tourism. Firstly, a significant proportion of tourism stakeholders in favour of policies supporting institutional control of local resources (a resources-control policy) might join the supporters of policies favouring institutional support for the supply of local tourism products (a products-supply policy). Going back to the Auvergne results derived from the simulations in the previous section, we see that the risk of concentrating tourism activities in a few places due to strict control of resources may be partly avoided if the proposed negotiation process is followed. Secondly, some stakeholders supporting a policy in favour of more cooperation between tourism stakeholders (a cooperation policy) might join those supporting the policy for more promotion of local products and places (a products and places-promotion policy). Again, returning to the earlier results, we see that the observed difference between stakeholders supporting a productssupply policy and stakeholders supporting a products and places promotion policy will increase in favour of the latter. Overall, the negotiation process might decrease the potential for conflicts among the tourism stakeholders, especially among the resource controllers and the institutions.

Participants to the scenario workshops recognised that encouraging tourists who come to stay here, requires more cooperative action among the different groups of tourism stakeholders, and that alignment of the positions of the different tourism stakeholders in the face of tourism projects requires more bottom-up approaches in policy design. 
Impacts of the negotiation process in Šumava Mountains (the Czech Republic). In the Šmava Mountains, simulations indicate that collaborative negotiations might persuade a significant proportion of resource controllers, tourism businesses, gatekeepers, host communities and institutions (currently reluctant to see an increase in the number of tourists that come for the area's natural and cultural resources) to join the supporters of tourismdevelopment policies.

Such shifts among the political positions might decrease the resources of moderators (i.e. those keeping a neutral position towards the hypothetical event), but the situation might remain a source of conflict, because a large proportion of the businesses, gatekeepers, resource controllers, and host communities (and some institutions) might remain reluctant to support tourism development. Simulations indicate that many conflicts could occur among stakeholders. Some of the institutions and resource controllers could challenge stakeholders, currently reluctant to promote tourism, to take a more pro-development stance. Some of the gatekeepers and other resource controllers, currently reluctant to promote tourism, could challenge other stakeholders to abandon their pro-development stance.

Impacts of the negotiation process in Evrytania (Greece). In Evrytania, as in Šumava Mountains, collaborative negotiations might challenge resource controllers, host communities and gatekeepers, who are currently reluctant to see an increase in the number of tourists, to join the supporters of tourism-development policies. But simulations also indicate that a significant proportion of other gatekeepers, resource controllers and businesses, which currently agree with tourism-development polices, might shift their position to join those holding a neutral position. 
Overall, those stakeholders neutral towards more tourists coming for the natural and cultural resources and the stakeholders in networks favouring more control over local resources, might gain in power, i.e. might increase their capacity to influence the evolution of tourism in the area. However, the networks supporting more cooperation among the tourism stakeholders might double their resources. As a result, the potential for conflicts among tourism stakeholders might increase, especially among institutions, resource controllers, and gatekeepers. Simulation results show that a great deal of conflict might develop between those institutions, resource controllers and gatekeepers that favour more 'natural and cultural' tourists and the institutions, resource controllers and gatekeepers that have adopted a neutral position towards this.

In the three study areas, simulations show that the results of the negotiation process are sensitive to the willingness of the most powerful and best resourced actors to negotiate with other actors, and to the current level of networking. An increase in the best resourced actors' willingness to accept the other stakeholders' requests to shift their political positions in the face of the event would increase the ability of the negotiation process to reduce the potential for conflicts among the tourism stakeholders. But a well resourced and well networked actor may actually be less inclined and less able to shift their political positions and this would decrease the ability of the negotiation process to reduce the potential for conflicts among stakeholders. Sometimes that willingness by the powerful to negotiate exists, with these effects, and sometimes it does not. Detailed data and tabulated results from the simulation exercises are available from the contact author upon request.

\section{Conclusions}


The Decision Support System (DSS) used here is a set of data-management procedures and multi-agent simulation models. Results from case-study applications indicate that the DSS provides policy makers with information on the likely impacts of integrated tourism management policies in a readily accessible form. The findings demonstrate that the DSS is able to process various inputs, analyse and 'understand' these inputs, and suggest courses of action which assist tourism actors in the diagnosis, planning, and design of their activities, especially in view of the relatively small scale of tourism in the respective study regions.

The DSS can be used for the construction of a variety of future scenarios by recording the perceptions of best practices and the preferences for resource use of the various tourism stakeholders. The DSS can also evaluate the tourism-development potential of alternative policies using the same inputs. The value of the DSS as a planning instrument lies in its ability to draw precise inferences about various management actions and policies, without needing to implement the decision or disturb any aspect of current tourism provision and, of course, without destroying any component of the existing policy framework. In addition, the DSS can help decision makers test the sensitivity of decisions with regard to uncertainties. These may be due to the spatial distribution of the local resources and activities in the area and to the distribution of the value of various parameters of the decision-making input (e.g. willingness of actors to negotiate and the importance of networking in the actors' decision making).

The simulation of actors' behaviour in the face of specified hypothetical tourism policies provided indications of the most appropriate strategies for the development of integrated tourism. For example, these simulations indicated how much change there might be in the use of local resources for tourism, the supply of tourism products, the distribution of tourism 
sites, tourists' satisfaction and the potential for inter-actor conflict. The simulations also indicated which types of informal linkages might appear within the inter- and intraorganisational decision-making arenas after collaborative negotiation processes have taken place.

Simulating the collaborative negotiations among tourism stakeholders provided complementary indications for the identification of the most appropriate institutional structures and strategies for the development of integrated tourism. The simulations showed that collaborative negotiations can operate as a mechanism by which tourism stakeholders might become more organised, sometimes more united, at others more polarised.

Collaborative negotiations establish a process by which tourism stakeholders acknowledge that their efforts to influence the policy domain are interconnected. The simulations showed that placing power at the centre of the discussion of, and the relationships among tourism stakeholders yields a deeper understanding of the possible future roles of stakeholders and resources in developing integrated tourism. The simulations also showed that collaborative negotiation processes can operate as a mechanism for multi-party dispute resolution and social integration. Empowerment and complementarity (SPRITE criteria for integrated rural tourism) may be enhanced by joint working, negotiation and compromise.

In general, the DSS methodology shows the important difference that political processes can make to the form, trajectory and degree of integration of tourism. The same policies may be favoured for completely different reasons in two case-study areas. Conversely, the same interests among stakeholders in different areas may reveal support for completely different policies. Thus, the spatial differences in how areas respond to comparable changes are not surprising. The outcomes of integrated rural tourism are not therefore predictable a priori. 
This shows that the development of integrated tourism in rural and lagging areas requires the heavy involvement of the local stakeholders and communities in the planning, implementation and assessment phases instead of ready-to-use and uniform solutions provided for by top-down policies. The development of integrated tourism is just one component of the wider rural-development task and, as such, bottom-up planning processes and decentralisation of policies should be the goal.

Of course, one should note that the proposed DSS approach is not easy to apply. The programme is built to address specific problems and issues and thus there is a lot of work, and possibly high cost, in creating the DSS. Furthermore, the DSS is data intensive for all actors and requires very extensive and expensive field work. However, once the programme has been built, it is fairly easy to alter the assumptions and derive a wide range of simulations under many scenarios, coordination patterns (policies) and negotiation processes.

\section{Acknowledgment}

This paper is based on a collaborative programme of research funded under the EU's Quality of Life and Management of Living Resources programme (QLK5-CT-2000-01211 SPRITE) and undertaken by the Universities of Wales (Aberystwyth) (co-ordinator), Caen, Patras, Ireland (Galway), Valencia, Lancaster and Coventry, together with the Institute of Landscape Ecology (České Budějovice), CEMAGREF (Clermont Ferrand) and Teagasc (Dublin).

The authors particularly thank Dr. Gordon Clark and an anonymous reviewer of this journal for their valuable comments and suggestions. 


\section{References}

Barreteau, O., Garin, P., Dumontier, A. \& Abrami, G. (2003) Agent-based facilitation of water allocation: case study in the Drome River valley, Group Decision and Negotiation, 12, pp. 441-461.

Bousquet, F. (1997) « Usage des ressources renouvelables et modélisation des représentations. Une approche par les SMA » Tendances nouvelles en modélisation pour l'environnement, Elsevier, pp. 187-196.

Bousset, J.P., Oliver, T. \& Jenkins, T.N. (2003) Decision Support System for Integrated Tourism (SPRITE Deliverable 18) (Clermont-Ferrand: Cemagref, Unité Dynamique et Fonctions de 1'Espace Rural).

Campbell, J. \& Townsley, P. (1997) Participatory and integrated policy processes in smallscale fisheries, PLA Notes, 30, pp. 66-69, (London: IIED).

Godet, M. (2001). Creating Futures: Scenario Planning as a Strategic Management Tool (London: Economica).

Gurung, T. R., F. Bousquet, and G. Trébuil. (2006) Companion modeling, conflict resolution, and institution building: sharing irrigation water in the Lingmuteychu Watershed, Bhutan. Ecology and Society 11(2): 36. [online] URL: http://www.ecologyandsociety.org/vol11/iss2/art36/ 
Happe, K., K. Kellermann, and A. Balmann (2006) Agent-based analysis of agricultural policies: an illustration of the agricultural policy simulator AgriPoliS, its adaptation, and behavior. Ecology and Society 11(1): 49. [online] URL:

http://www.ecologyandsociety.org/vol11/iss1/art49/.

Jenkins, T.N. \& Oliver, T. (2001) Integrated Tourism: a Conceptual Framework (Aberystwyth: University of Wales).

Stokman, F.N. \& Zeggelink, E.P.H. (1996) Is politics power or policy oriented? A comparative analysis of dynamic access models in policy networks, Journal of Mathematical Sociology, 21(1-2), pp. 77-111.

Street, P. (1997) "Scenario Workshops: A participatory approach to sustainable urban living?" Futures, 29(2), 139-158. 